\title{
Impact of priming the infusion system on the performance of target-controlled infusion of remifentanil
}

\author{
Jong-Yeop Kim ${ }^{1}$, Bong-Ki Moon ${ }^{1}$, Jong Hyuk Lee ${ }^{1}$, Youn Yi Jo ${ }^{2}$, and Sang-Kee Min ${ }^{1}$ \\ Department of Anesthesiology and Pain Medicine, ${ }^{1}$ Ajou University School of Medicine, Suwon, ${ }^{2}$ Gachon University Gil Medical \\ Center, Incheon, Korea
}

Background: The start-up behavior of syringe and syringe pump is known to be one of the causes of inaccurate intravenous infusion. This study evaluated the method of priming the infusion system (PRIMING), and its impact on the target-controlled infusion (TCI) of two remifentanil diluents.

Methods: PRIMING was performed using an evacuation of $2.0 \mathrm{ml}$ to the atmosphere prior to TCI. Forty-eight TCI, using $50 \mu \mathrm{g} / \mathrm{ml}\left(\right.$ Remi $\left._{50}\right)$ or $20 \mu \mathrm{g} / \mathrm{ml}\left(\right.$ Remi $_{20}$ ) of diluents, were performed targeting $4.0 \mathrm{ng} / \mathrm{ml}$ of effect-site concentration $\left(\mathrm{C}_{\text {eff }}\right)$, with PRIMING or not. The gravimetrical measurements of the delivered infusates reproduced actual $\mathrm{C}_{\text {eff. }}$ The bolus amount and time to reach $95 \%$ target were compared.

Results: Without PRIMING, Remi ${ }_{50}$ infused less bolus (43 $\pm 23 \%$ ) than $\operatorname{Remi}_{20}(19 \pm 9 \%)(\mathrm{P}=0.003)$, and showed more delayed increase of $\mathrm{C}_{\text {eff }}(11.2 \pm 4.0 \mathrm{~min})$ than $\operatorname{Remi}_{20}(7.4 \pm 0.4 \mathrm{~min})(\mathrm{P}=0.028)$. However, PRIMING significantly decreased the deficit of the bolus $\left(2 \pm 1 \%\right.$ ), as well as the delay of the increase of $\mathrm{C}_{\text {eff }}$ in $\operatorname{Remi}_{50}(1.2 \pm 0.2 \mathrm{~min}$ ) (both $\mathrm{P}$ $<0.001$ ). In addition, with PRIMING, the start-up bolus showed minimal difference to the nominal bolus ( 1 and $2 \%$ ), and $\mathrm{C}_{\text {eff }}$ were increased to $4.0 \pm 0.1 \mathrm{ng} / \mathrm{ml}$ at the expected time of peak effect, irrespective of the diluents.

Conclusions: Proper operation of the syringe pump used in the priming of the syringe may be helpful in reduction of the inaccuracy of TCI, particularly during the early phase of infusion, or the infusion of a more concentrated diluent. (Korean J Anesthesiol 2013; 64: 407-413)

Key Words: Drug delivery, Priming, Target-controlled infusion.

Received: July 27, 2012. Revised: September 22, 2012. Accepted: October 25, 2012.

Corresponding author: Sang-Kee Min, M.D., Department of Anesthesiology and Pain Medicine, Ajou University School of Medicine, San 5, Wonchon-dong, Yeongtong-gu, Suwon 443-721, Korea. Tel: 82-31-219-5572, Fax: 82-31-219-5574, E-mail: anesmin@nate.com

(c) This is an open-access article distributed under the terms of the Creative Commons Attribution Non-Commercial License (http:// creativecommons.org/licenses/by-nc/3.0/), which permits unrestricted non-commercial use, distribution, and reproduction in any medium, provided the original work is properly cited. 


\section{Introduction}

Target-controlled infusion (TCI) using pharmacokinetic (PK) and pharmacodynamic (PD) models of intravenous anesthetics have been used in clinical settings, with an acceptable range of performance errors [1-3]. Error sources are believed to be related to the software and hardware of the infusion machine, as well as PK/PD variability. As such, the proper choice of machine and $\mathrm{PK} / \mathrm{PD}$ model is essential for the accurate administration of a drug. Particular attention must be paid to the infusion device and the assembly to reduce the inaccuracy of TCI. One of the causes of inaccuracy in the infusion behavior using a syringe pump is the start-up delay, and the underlying mechanisms are reported to include: free-play at the syringe flange cradle $[4,5]$; use of an antisyphon valve [6,7]; and differences in the syringe plunger designs [8]. In addition, the method of priming the infusion system has been known to be effective on a rapid startup and achievement of pre-set flow rate [5]. However, most results have indicated on the time delay of start-up infusion, and the infusion rates were very slow $(1.0 \mathrm{ml} / \mathrm{h})$. In addition, reports on the adequate priming volume of a specific pump/ syringe combination are rare.

This study attempted to determine the adequate priming volume for the infusion system, and investigated the extent of a possible delay of the drug effect which would result from mechanical defects of the infusion system, with or without priming the infusion system, using direct gravimetrical measurements of virtual infusate amounts during TCI of 2 remifentanil diluents.

\section{Materials and Methods}

This study was approved by the Institutional Review Board, and performed as a bench experiment using $60 \mathrm{ml}$ syringes (BD $60 \mathrm{ml}$ Syringe, Luer-Lok ${ }^{\mathrm{TM}}$ Tip, BD, USA) and syringe pumps (PILOTE ANETHESIE 2 IS $^{\circledR}$, Fresenius Vial, Le Grand Chemin, Brezins, France). Three syringe pumps were randomly used, and calibrated by qualified personnel (zero calibration for $6 \pm 0.05 \mathrm{~V}$; and pressure calibration for $600 \mathrm{mmHg}$ ) prior to the experiment. Randomizations were performed using the Microsoft ${ }^{\circledR}$ Excel randomization function.

A preliminary test was performed in order to estimate the range of possible free-play of syringe in the syringe pump used for this study, and to determine an adequate priming volume for the infusion system. Fig. 1A shows the assembly of syringe pump-syringes-stopcocks. Twelve $60 \mathrm{ml}$ syringes (4 syringes per pump) were randomly tested, and a two-step approach was used. The display panel of the pump was switched to the syringe driving pressure mode. Step I: After locking the stopcocks of 1 $\mathrm{ml}$ syringes, the fluid was forcefully aspirated from the $60 \mathrm{ml}$ syringe using the $10 \mathrm{ml}$ syringe, until the finger flange was ready to detach from the syringe drive. This step made the syringe barrel slide toward the right side of the pump (gray arrow lines, (1)). Following that, the aspiration was released, and no pressure on the plunger was maintained. Step II: After locking the stopcocks of $10 \mathrm{ml}$ syringes, fluids in $1 \mathrm{ml}$ syringes were infused successively into the $60 \mathrm{ml}$ syringe. This caused the finger flange to move forward, and the thumb rest to push the syringe drive (gray arrow lines (2)). Forceful infusion continued until the syringe drive pressure reached $500 \mathrm{mmHg}$, then slow aspiration was performed until the pressure decreased to 50 mmHg. The infused volumes using $1 \mathrm{ml}$ syringes during Step II were determined as a reference volume for the priming. The mean volume was $1.27 \pm 0.107 \mathrm{ml}$. Therefore, $2.0 \mathrm{ml}(\fallingdotseq 1.905$ $\mathrm{ml}$ ) was determined as the priming volume, taking $50 \%$ more of the result.
A

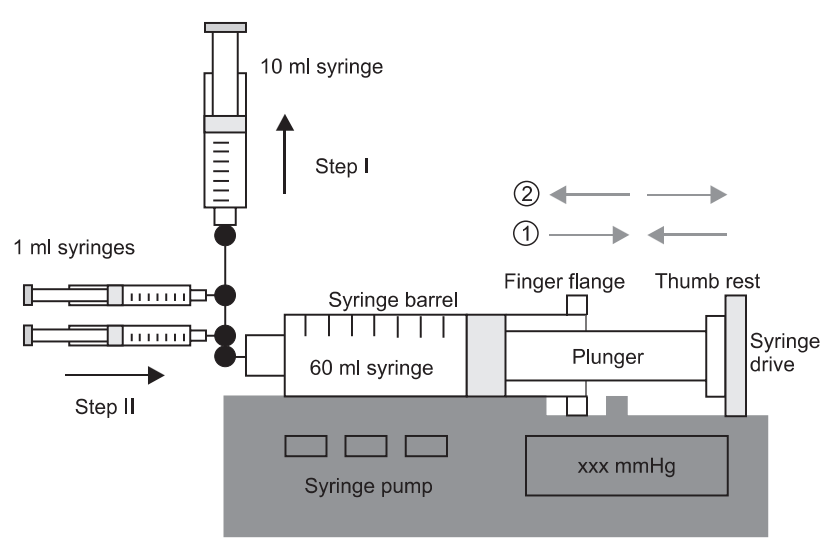

B

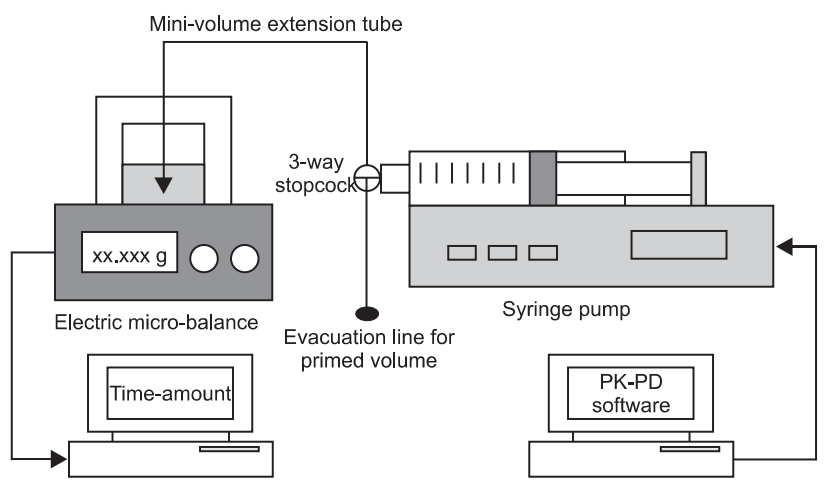

Fig. 1. Assembly of the preliminary test for determination of the priming volume of a $60 \mathrm{ml}$ syringe and syringe pump (A) and infusion assembly for the target-controlled infusion of virtual diluents of remifentanil (B). PK: pharmacokinetic, PD: pharmacodynamic. 
The diagram of the experimental TCI is illustrated in Fig. 1B. Sterile distilled water was used as virtual aqueous solution. It was attempted to fill the infusion assembly with distilled water without air. The tip of the syringe was maintained at the same height with the surface of the solution in the sampling glass before the start of the infusion to minimize a fluid-shift during infusion. Six physicians and nurses randomly installed the syringe into the pump. They had over 3 years of experience with anesthetic practice and did not know the final end-point of the study. Prior to establishing communication linkage between the pump and PK software, priming of the infusion system (PRIMING) was performed using the evacuation of $2.0 \mathrm{ml}$ from the infusion assembly to the atmosphere through the evacuation line, while pressing the purge button after the syringe brand confirmation. In the no-PRIMING group, TCI was initiated without purging the system.

Forty eight experimental TCIs, targeting an effect-site concentration $\left(\mathrm{C}_{\text {eff }}\right)$ of $4.0 \mathrm{ng} / \mathrm{ml}$, were randomly performed using $50 \mu \mathrm{g} / \mathrm{ml}\left(\mathrm{Remi}_{50}\right)$ or $20 \mu \mathrm{g} / \mathrm{ml}\left(\mathrm{Remi}_{20}\right)$ of remifentanil, and with or without PRIMING, independently. TCI was performed using PK/PD software (Asan pump, version 1.3, Bionet Co., Seoul, Korea) using the model of Minto et al. [9]. Covariates sets (gender, age, body weight, and height) were collected randomly from the electric medical records of the patients (age 20-70 yr, body weight not exceeding $20 \%$ of the ideal body weight), who had undergone general anesthesia in December, 2010. The syringe was replaced about $1 \mathrm{~h}$ after the start of TCI, and the duration was limited to within $60 \mathrm{sec}$. After the syringe replacement, the system was also primed in the PRIMING group and not primed in the no-PRIMING group, and thereafter, an additional $30 \mathrm{~min}$ of TCI was maintained. The TCI data files, including predicted plasma $\left(\mathrm{C}_{\mathrm{p} \text {-proper }}\right)$ and effectsite $\left(\mathrm{C}_{\text {eff-proper }}\right)$ concentrations were saved on the hard-disk. On occasions of gross leakage of fluid from the infusion assembly and air delivery into the sampling glass on visual inspection, the experiment was discarded and implemented again from the first step.

During TCI, cumulative weights of the delivered solution were gravimetrically measured using an electric microbalance (FX-300i, A\&D Co, Korea) and saved on a hard disk using the RS232 interface software (RrKey Ver. 1.34, A\&D Co, Korea). The weight was converted to volume, assuming a conversion of 1 $\mathrm{g}$ of distilled water equaling $1.0029 \mathrm{ml}$ (water temperature was $23-25^{\circ} \mathrm{C}$ ). Infusion data was converted into a file formatted with time ( $\mathrm{min})$ vs. unit infusion rate $(\mu \mathrm{g} / \mathrm{min})$ columns, and the STANPUMP ${ }^{\odot}$ simulated the actual time courses of the plasma $\left(\mathrm{C}_{\mathrm{p} \text {-rep }}\right)$ and effect-site $\left(\mathrm{C}_{\text {eff-rep }}\right)$ concentration.

We compared the absolute percentage differences between the nominal bolus and the measured amount $\left(\mathrm{PD}_{\text {Bolus }}=100 \times\right.$ bolus difference / nominal bolus), and the time to reach $95 \%$ target $\left(\mathrm{T}_{95 \% \text { target }}\right)$ during the start-up period and after syringe replacement. The $\mathrm{C}_{\text {eff-rep }}$ at the time to peak effect $\left(\mathrm{C}_{\mathrm{t} \text {-peak }}\right)$ during the start-up period and minimal $\mathrm{C}_{\text {eff-rep }}$ during syringe replacement were compared between the groups. The performance error (PE) of each TCI was evaluated using the methodology proposed by Varvel et al. [10] and calculated as follows:

$$
P E(\%)=100 \times \frac{C_{p-\text { rep }}-C_{p-\text { proper }}}{C_{p \text {-proper }}}
$$

A bias (median performance error; MDPE) and an inaccuracy (median absolute performance error; MDAPE) were independently determined for the start-up performance ( 0 to $10 \mathrm{~min}$ ) and the maintenance performance (10 $\mathrm{min}$ to syringe replacement). Performance errors within $\pm 5.0 \%$ were considered as an acceptable range of infusion accuracy in this study.

SPSS 13.0 for the Windows (SPSS Inc, Chicago, IL, USA) was used for statistical analyses. Data are expressed as mean \pm SD or number of patients. Continuous variables during start-up periods and syringe replacement were separately compared in the one-way analysis of variance. Post hoc analyses were carried out using Scheffé's adjustment for multiple comparisons. A P value $<0.05$ was considered statistically significant.

\section{Results}

The demographic covariate-sets for TCI were not significant between the four groups (Table 1). Time courses of $\mathrm{C}_{\text {eff-rep }}$ during the four kinds of TCI are illustrated in Fig. 2, and gray bands indicate the ranges within $\pm 5 \%$ of target concentration.

During the start-up period (Table 2), Remi ${ }_{50}$ without PRIMING showed more $\mathrm{PD}_{\text {Bolus }}(\mathrm{P}=0.003)$ and less $\mathrm{C}_{\mathrm{t} \text {-peak }}(\mathrm{P}=0.004)$, and took longer for $\mathrm{C}_{\text {eff }}$ to reach $95 \%$ of the target concentration $(\mathrm{P}=$ 0.028) than Remi $_{20}$. However, this bolus deficit and the delayed increase of the $\mathrm{C}_{\text {eff }}$ of $\mathrm{Remi}_{50}$, were significantly improved with PRIMING $(\mathrm{P}<0.001)$. With PRIMING, the bolus difference between the nominal and measured amount was minimal (1 and $2 \%$ ), irrespective of the diluent of remifentanil, and the $\mathrm{C}_{\text {eff }}$ increased to $4.0 \pm 0.1 \mathrm{ng} / \mathrm{ml}$ at the expected time to peak effect

Table 1. Characteristics of Patient Covariate Sets

\begin{tabular}{lccccc}
\hline & \multicolumn{2}{c}{ No PRIMING } & & \multicolumn{2}{c}{ PRIMING } \\
\cline { 2 - 3 } \cline { 5 - 6 } & $\begin{array}{c}\text { Remi }_{50} \\
(\mathrm{n}=12)\end{array}$ & $\begin{array}{c}\text { Remi }_{20} \\
(\mathrm{n}=12)\end{array}$ & & $\begin{array}{c}\text { Remi }_{50} \\
(\mathrm{n}=12)\end{array}$ & $\begin{array}{c}\text { Remi }_{20} \\
(\mathrm{n}=12)\end{array}$ \\
\hline Sex (M/F) & $7 / 5$ & $6 / 6$ & & $6 / 6$ & $6 / 6$ \\
Age (yr) & $39 \pm 12$ & $44 \pm 15$ & & $45 \pm 13$ & $42 \pm 14$ \\
Weight (kg) & $67 \pm 10$ & $64 \pm 8$ & & $70 \pm 8$ & $65 \pm 7$ \\
Height (cm) & $168 \pm 9$ & $168 \pm 7$ & & $171 \pm 7$ & $167 \pm 9$ \\
\hline
\end{tabular}

Values are mean \pm SD or number of patients. PRIMING: priming of the infusion system. 
A
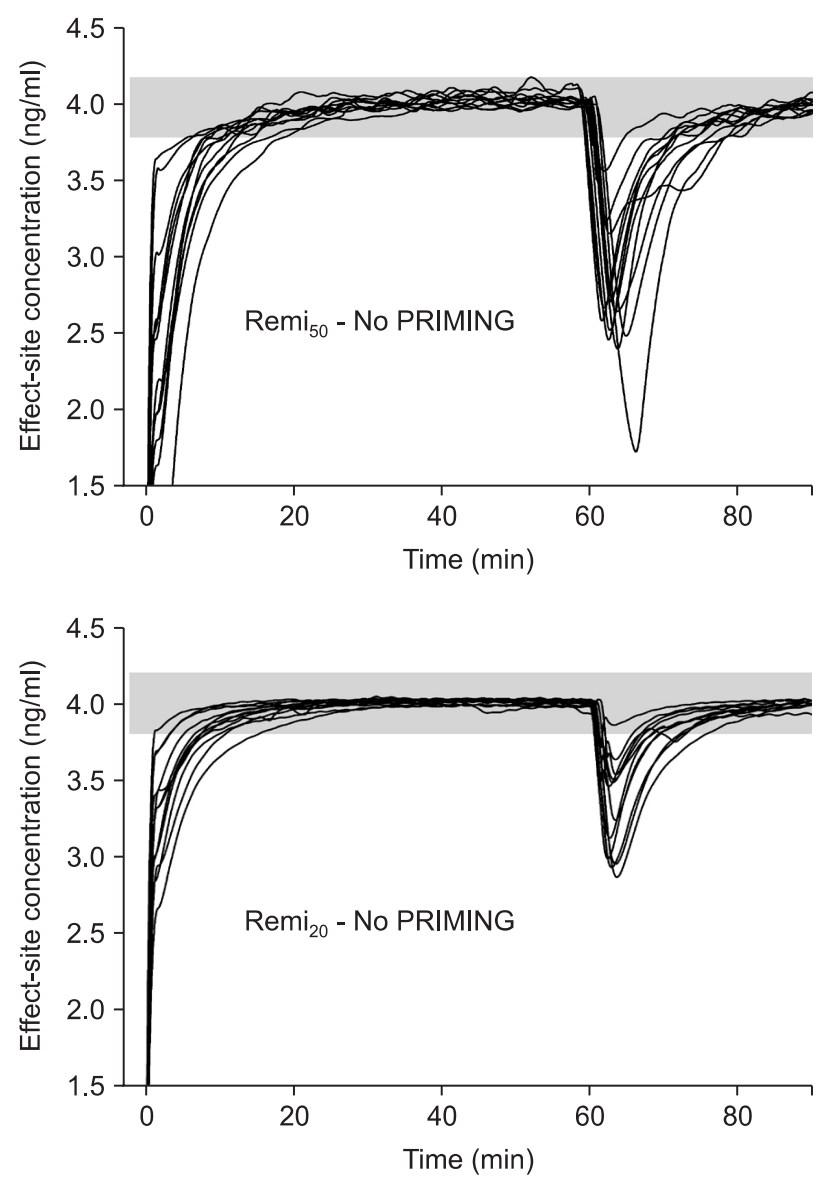

B
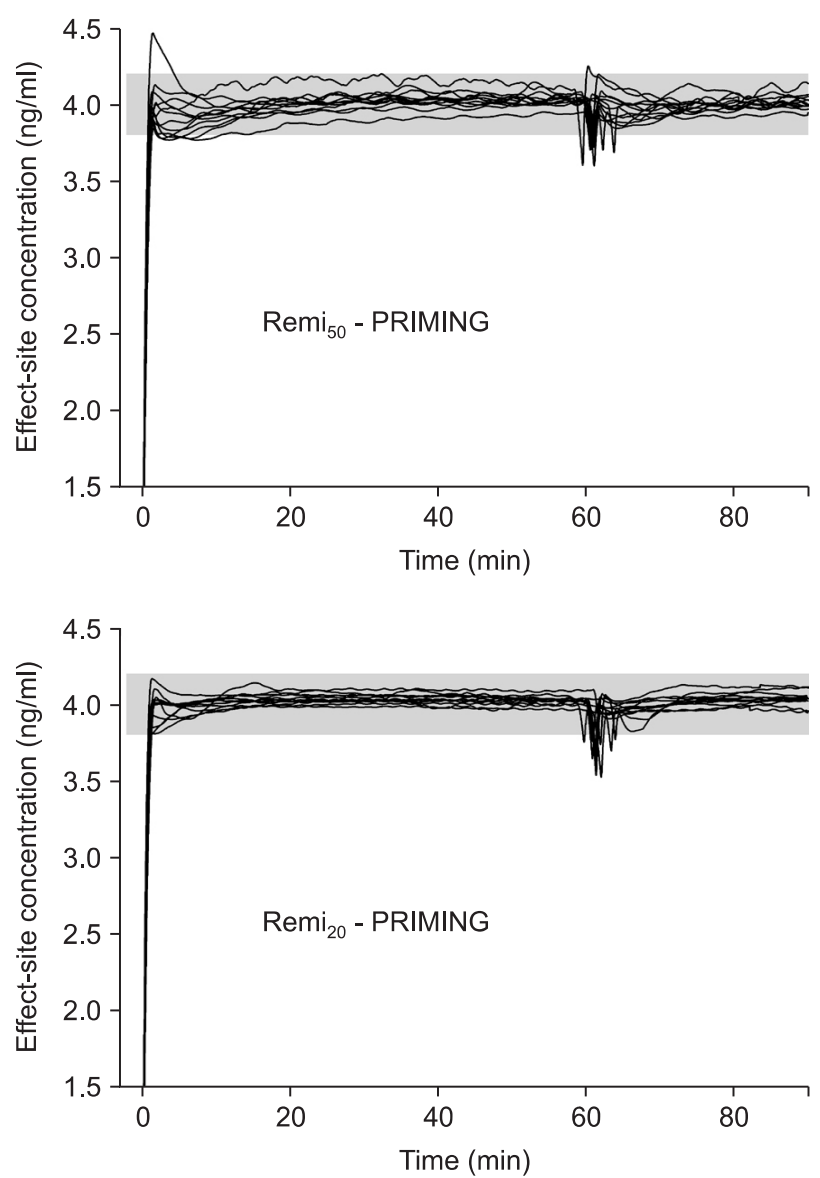

Fig. 2. Time-courses of the reproduced individual effect-site concentration of $50 \mu \mathrm{g} / \mathrm{ml}\left(\mathrm{Remi}_{50}\right)$ and $20 \mu \mathrm{g} / \mathrm{ml}\left(\mathrm{Remi}_{20}\right)$ of remifentanil virtual diluents, targeting $4.0 \mathrm{ng} / \mathrm{ml}$ of effect-site concentration, with either priming the infusion system (B) or not (A). Gray bands indicate the range of $\pm 5 \%$ of the target concentration. PRIMING: priming of the infusion system.

Table 2. Bolus Differences and the Effect-Site Concentration of Remifentanil during the Start-up Period and Syringe Replacement

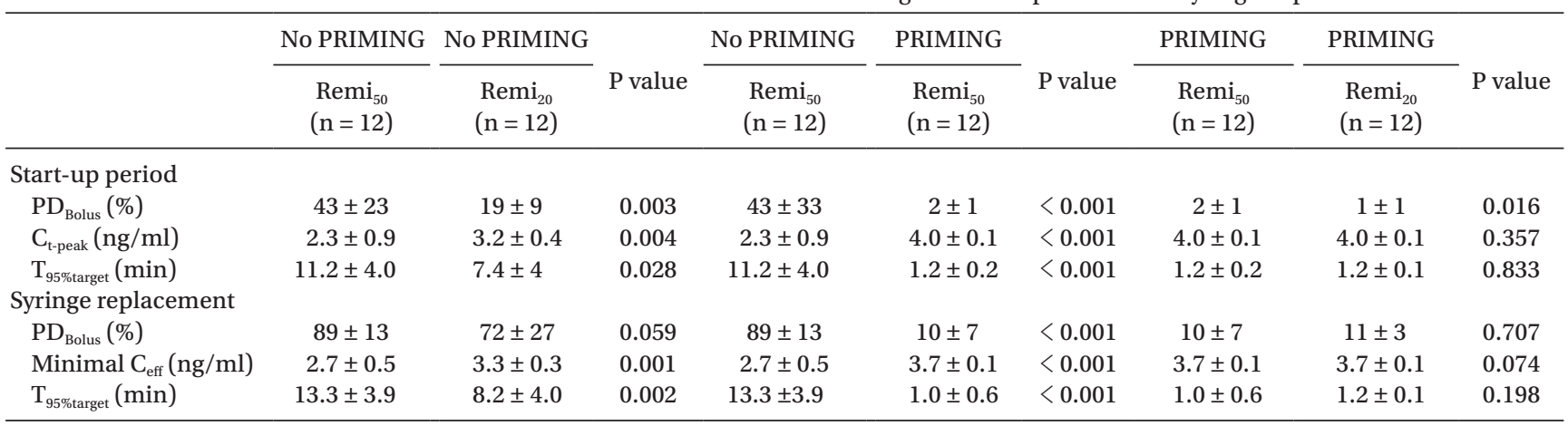

Values are mean $\pm \mathrm{SD}$. $\mathrm{PD}_{\text {Bolus }}$ : absolute percentage difference between the nominal and the measured bolus, $\mathrm{C}_{\mathrm{t} \text {-peak }}$ : the effect-site concentration of remifentanil at the time of peak effect, $\mathrm{T}_{95 \% \text { target }}$ : time to reach $95 \%$ of target concentration. PRIMING: priming of the infusion system.

(1.5 $\pm 0.2 \mathrm{~min}$; min-max was $1.1-2.0 \mathrm{~min})$.

During syringe replacement (Table 2), Remi ${ }_{50}$ without PRIMING led a greater decrease of $\mathrm{C}_{\text {eff }}(\mathrm{P}=0.001)$ and took longer for $\mathrm{C}_{\text {eff }}$ to recover to the $95 \%$ target level than $\operatorname{Remi}_{20}$.
However, the bolus deficit and the delayed recovery of $\mathrm{C}_{\text {eff }}$ during Remi ${ }_{50}$, were also significantly improved with PRIMING $(\mathrm{P}<0.001)$. With PRIMING, the $\mathrm{PD}_{\text {Bolus }}$ were not significant between the diluents, and $\mathrm{C}_{\text {eff }}$ rapidly recovered to the target 
A
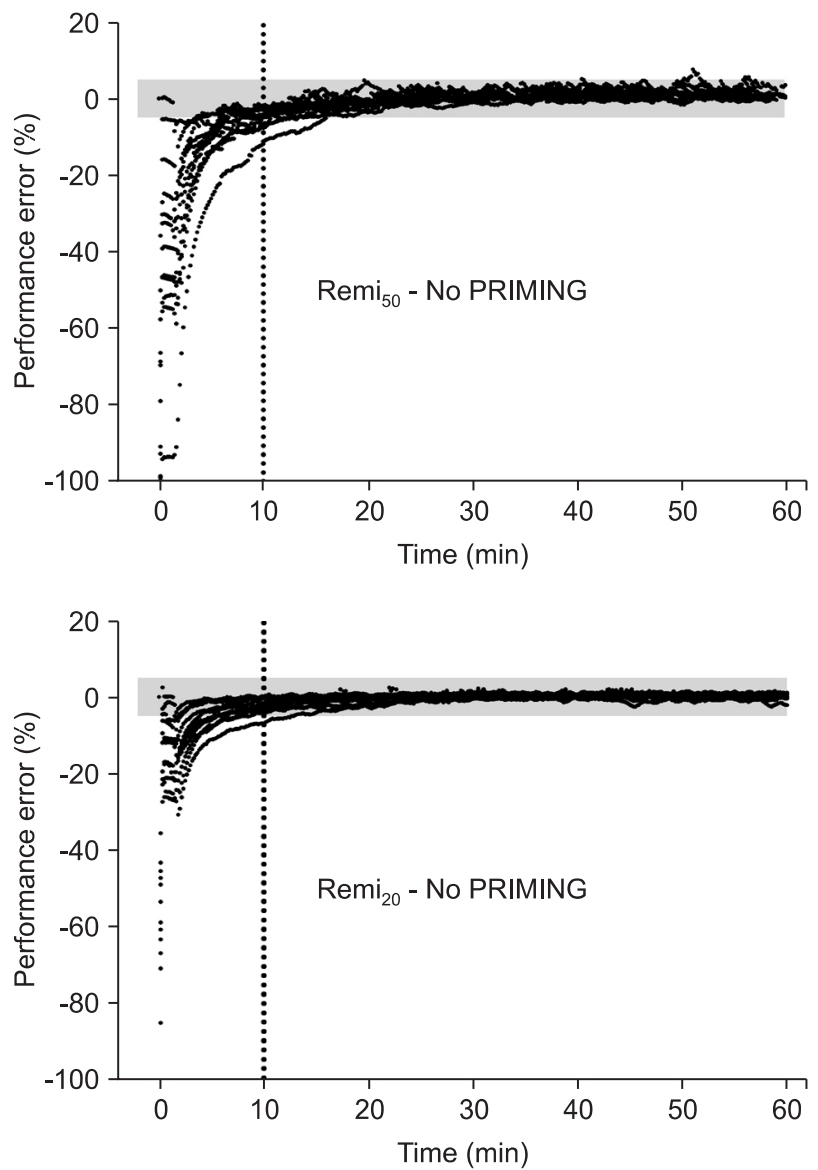

B
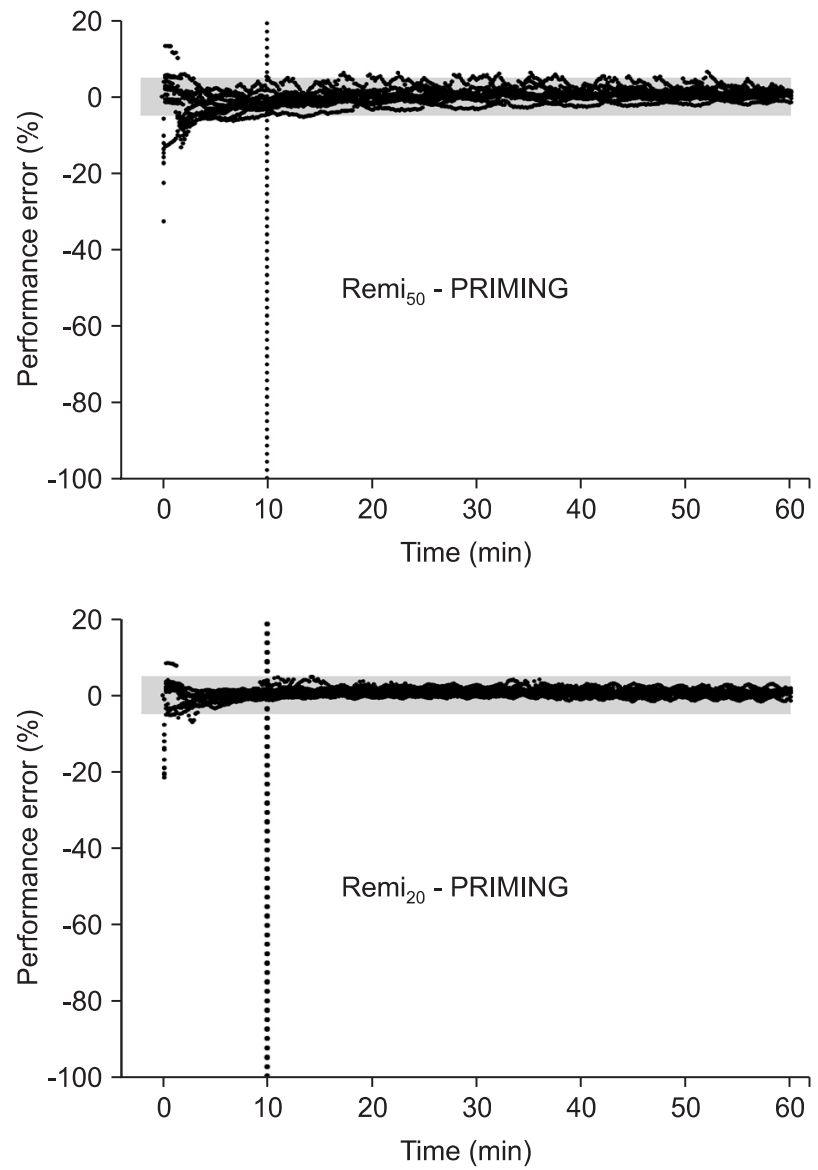

Fig. 3. Time-courses of the performance errors of plasma concentration of $50 \mu \mathrm{g} / \mathrm{ml}\left(\mathrm{Remi}_{50}\right)$ and $20 \mu \mathrm{g} / \mathrm{ml}\left(\mathrm{Remi}_{20}\right)$ of remifentanil virtual diluents, targeting $4.0 \mathrm{ng} / \mathrm{ml}$ of effect-site concentration, with either priming the infusion system (B) or not (A). Gray bands indicate the range of $\pm 5 \%$ of performance errors. PRIMING: priming of the infusion system.

Table 3. Start-up and Maintenance Performances of the Target-controlled Infusion of Remifentanil

\begin{tabular}{|c|c|c|c|c|c|c|c|c|c|}
\hline & No PRIMING & No PRIMING & \multirow[b]{2}{*}{$P$ value } & No PRIMING & PRIMING & \multirow[b]{2}{*}{$P$ value } & PRIMING & PRIMING & \multirow[b]{2}{*}{$P$ value } \\
\hline & $\begin{array}{l}\text { Remi }_{50} \\
(\mathrm{n}=12)\end{array}$ & $\begin{array}{l}\text { Remi }_{20} \\
(\mathrm{n}=12)\end{array}$ & & $\begin{array}{l}\text { Remi }_{50} \\
(\mathrm{n}=12)\end{array}$ & $\begin{array}{l}\text { Remi }_{50} \\
(\mathrm{n}=12)\end{array}$ & & $\begin{array}{l}\text { Remi }_{50} \\
(\mathrm{n}=12)\end{array}$ & $\begin{array}{l}\text { Remi }_{20} \\
(\mathrm{n}=12)\end{array}$ & \\
\hline \multicolumn{10}{|l|}{ Start-up } \\
\hline MDPE (\%) & $\begin{array}{c}-10.5^{*} \\
(-14.7 \text { to }-6.8)\end{array}$ & $\begin{array}{c}-5.0^{*} \\
(-6.9 \text { to }-3.0)\end{array}$ & 0.005 & $\begin{array}{c}-10.5^{*} \\
(-14.7 \text { to }-6.8)\end{array}$ & $\begin{array}{c}-1.9 \\
(-3.4 \text { to } 0.4)\end{array}$ & $<0.001$ & $\begin{array}{c}-1.9 \\
(-3.4 \text { to } 0.4)\end{array}$ & $\begin{array}{c}-0.2 \\
(-0.8 \text { to } 0.4)\end{array}$ & 0.705 \\
\hline MDAPE (\%) & $\begin{array}{c}10.5 \\
\text { (6.8 to } 14.2)\end{array}$ & $\begin{array}{c}5.0 \\
(3.0 \text { to } 7.0)\end{array}$ & 0.008 & $\begin{array}{c}10.5 \\
\text { (6.8 to } 14.2)\end{array}$ & $\begin{array}{c}2.6 \\
(1.6 \text { to } 3.6)\end{array}$ & $<0.001$ & $\begin{array}{c}2.6 \\
(1.6 \text { to } 3.6)\end{array}$ & $\begin{array}{c}1.0 \\
(0.6 \text { to } 1.4)\end{array}$ & 0.731 \\
\hline \multicolumn{10}{|l|}{ Maintenance } \\
\hline MDPE (\%) & $\begin{array}{c}0.5 \\
(-0.04 \text { to } 1.0)\end{array}$ & $\begin{array}{c}-0.04 \\
(-0.3 \text { to } 0.2)\end{array}$ & 0.619 & $\begin{array}{c}0.5 \\
(-0.04 \text { to } 1.0)\end{array}$ & $\begin{array}{c}0.5 \\
(-0.5 \text { to } 1.3)\end{array}$ & 1.000 & $\begin{array}{c}0.5 \\
(-0.5 \text { to } 1.3)\end{array}$ & $\begin{array}{c}0.8 \\
(-0.3-1.2)\end{array}$ & 0.867 \\
\hline MDAPE (\%) & $\begin{array}{c}1.2 \\
\text { (0.9 to } 1.5)\end{array}$ & $\begin{array}{c}1.0 \\
(0.8 \text { to } 1.3)\end{array}$ & 0.065 & $\begin{array}{c}1.2 \\
\text { (0.9 to } 1.5)\end{array}$ & $\begin{array}{c}1.2 \\
\text { ( } 0.6 \text { to } 1.8)\end{array}$ & 0.946 & $\begin{array}{c}1.2 \\
\text { ( } 0.6 \text { to } 1.8 \text { ) }\end{array}$ & $\begin{array}{c}0.9 \\
(0.5-1.3)\end{array}$ & 0.364 \\
\hline
\end{tabular}

Values are percent (95\% confidence interval). *Significant bias (95\% confidence interval of MDPE did not include zero). PRIMING: priming of the infusion system.

level, irrespective of the diluent.

Fig. 3 shows the time courses of performance error. Without PRIMING, start-up performances (Table 3) showed significant negative biases in the TCI of both diluents (95\% confidence intervals of MDPE did not include zero), and the inaccuracy was greater in $\mathrm{Remi}_{50}$ than in $\operatorname{Remi}_{20}(\mathrm{P}=0.008)$. However, PRIMING 
led Remi $_{50}$ to have no bias and decreased the inaccuracy of Remi $_{50}(\mathrm{P}<0.001)$. With PRIMING, both TCI showed no bias and the inaccuracy was less than $5 \%$, irrespective of the diluents. The maintenance performances (Table 3) showed no bias in the TCI of both diluents, whether PRIMING or not, and inaccuracies were low, which were not significantly different between all groups $(\mathrm{P}>0.05)$.

\section{Discussion}

We investigated the efficacy of priming the infusion system on the performance of remifentanil TCI. By priming the system, we could effectively achieve the predicted time-course of the predicted concentrations of the drug in the body, especially during the early phase of infusion and after the replacement of the syringe.

The start-up delay in drug delivery that occurred in the absence of priming as a result of the engagement of gears in the mechanical drive and compliance of the syringe has previously been recognized and reported $[4,5,8]$. However, many users of TCI remain unaware of the advantages of priming the infusion system with the purge button, and there is a lack of information on the magnitude of the effects and the clinical significance with different drug concentrations while using the syringe pump model. Thus, this study investigated the PK/PD courses that resulted from a potential mechanical flaw during the adult TCI of remifentanil. Remifentanil has been known to have a smaller central compartment, which implies that it requires a smaller bolus than other opioids or propofol. Therefore, it had been anticipated that the TCI regimen of remifentanil could be vulnerable to the start-up delay. Without PRIMING, the reproducing simulation showed a distinct delayed increase of $\mathrm{C}_{\text {eff }}$, which was more prominent during the start-up phase, as well as after the syringe installation. This delay was more distinct during the TCI of lesser-diluted drug preparation, but with PRIMING, the start-up bolus did not differ from the nominal bolus, and $\mathrm{C}_{\text {eff }}$ was increased within the expected time, regardless of the diluent.

Without PRIMING, the lesser amounts of the drug were always administered, while start-up MDPE showed a negative bias. This could be a problem during the induction of anesthesia. The TCI regimen of Remi ${ }_{50}$ preparations in this study infused 1.32 or $1.34 \mathrm{ml}$ as start-up boluses. However, the actual predicted $\mathrm{C}_{\text {eff }}$ remained $57.8 \%$ of the target at the time to peak effect, and the minimal $\mathrm{C}_{\text {eff }}$ then was $0.02 \mathrm{ng} / \mathrm{ml}$. It also took $11.6 \mathrm{~min}$ to reach the target concentration. Therefore, it is unlikely that the TCI system can afford an accurate time-course of $\mathrm{C}_{\mathrm{p}}$ and $\mathrm{C}_{\text {eff }}$. It also displays a false steady state after the time to peak effect. Therefore, the actual level of analgesia during this period would be insufficient for certain procedures, such as tracheal intubation or skin incision.

After syringe replacement during surgery, without PRIMING, four cases of Remi ${ }_{50}$ could not push the bolus, and the $\mathrm{C}_{\text {eff }}$ maximally decreased below half of the target. Under clinical settings, the syringe replacement may take longer than what was observed in this study, as contaminations need to be avoided, and complex infusion assembly may be difficult to manipulate. Therefore, PRIMING would be more appropriate after the syringe replacement during surgery, in order to prevent a greater decrease of drug concentration, which may exceed the results obtained in this experiment.

Without PRIMING, the maximal bolus deficits were $1.18 \mathrm{ml}$ in $\mathrm{Remi}_{50}$ and $1.08 \mathrm{ml}$ in $\mathrm{Remi}_{20}$, which were similar to the results of the preliminary test $(1.27 \mathrm{ml})$. Step I of this test led the syringe to the worst position in the pump, whereas Step II offered the syringe the best status in the pump. As such, the syringe is positioned randomly between the two extremes after routine syringe installation. However, PRIMING would cause the syringe flange to shift forward maximally in the syringe flange cradle, and make the syringe drive to hold the thumb rest tightly, while being ready to push the plunger promptly and accurately.

In the authors' clinical settings, these observations were occasionally found: the free-play of the finger flange in the syringe flange cradle as reported [11]; a loose fit between the thumb rest and the syringe drive; and sometimes the plunger not maintaining a horizontal position following visual inspection. It was also inferred that the cross-sectional area of the internal barrel space and thickness of the finger flange may be additional factors for the start-up delay. To reduce these mechanical shortcomings during infusion, it would be helpful to choose the syringe pump model with the least free-play of syringe in the pump [11], or with a specially designed module, such as FASTSTART [5]. However, the best pump-syringe combination that shows the least start-up delay is not always available in the clinical settings, and TCI is not always compatible with every pump. As such, if the infusion system is primed using a pre-determined pump/syringe-specific volume, the modeldependent differences can be overcome, and the accurate infusion rate ordered by the TCI system can be rapidly achieved, without any delays of the drug effects.

There may be some caveats in this study. First, the participants who installed the syringe in this study were not experts in the infusion technology. More rigorous preparation after the education of the start-up infusion behavior may reduce the delay of infusion. Second, a zero-pressure gradient to the infusion assembly was maintained. However, in clinical settings using multi-line infusions to the gravity-line, the pressure within the infusion route would be maintained at a higher level than that of this study setting. Therefore, in vivo infusion may be changeably decreased, according to various factors. Third, 
in the use of the antisyphon valve, the start-up infusion can be changed [6]. The compliance of this study's infusion assembly was reported to be $1.33 \mu \mathrm{l} / \mathrm{mmHg}$ [12]. If the crack pressure of antisyphon valve is $150 \mathrm{mmHg}, 0.199 \mathrm{ml}$ of infusate is needed to open the valve. As such, a lower amount will be infused during the start-up period, without PRIMING.

Priming the infusion system is not a mandatory process that needs to be verified by the user at the start of the infusion of various intravenous agents, and may even be regarded as a minor process. However, the data in this study indicate that the priming of the infusion system may useful in reducing the delay of drug effects and the inaccuracy of the infusion system, especially after initiating the infusion, or during the infusion of a more concentrated diluent.

\section{References}

1. Glen JB, Servin F. Evaluation of the predictive performance of four pharmacokinetic models for propofol. Br J Anaesth 2009; 102: 62632.

2. Swinhoe CF, Peacock JE, Glen JB, Reilly CS. Evaluation of the predictive performance of a 'Diprifusor' TCI system. Anaesthesia 1998; 53 Suppl 1: 61-7.

3. White M, Kenny GN, Schraag S. Use of target controlled infusion to derive age and gender covariates for propofol clearance. Clin Pharmacokinet 2008; 47: 119-27.
4. Neff T, Fischer J, Fehr S, Baenziger O, Weiss M. Start-up delays of infusion syringe pumps. Paediatr Anaesth 2001; 11: 561-5.

5. Neff T, Fischer J, Fehr S, Baenziger O, Weiss M. Evaluation of the FASTSTART mode for reducing start-up delay in syringe pump infusion systems. Swiss Med Wkly 2001; 131: 219-22.

6. McCarroll C, McAtamney D, Taylor R. Alteration in flow delivery with antisyphon devices. Anaesthesia 2000; 55: 355-7.

7. Lannoy D, Décaudin B, Dewulf S, Simon N, Secq A, Barthélémy C, et al. Infusion set characteristics such as antireflux valve and deadspace volume affect drug delivery: an experimental study designed to enhance infusion sets. Anesth Analg 2010; 111: 1427-31.

8. Weiss M, Fischer J, Neff T, Baenziger O. The effects of syringe plunger design on drug delivery during vertical displacement of syringe pumps. Anaesthesia 2000; 55: 1094-8.

9. Minto CF, Schnider TW, Egan TD, Youngs E, Lemmens HJ, Gambus $\mathrm{PL}$, et al. Influence of age and gender on the pharmacokinetics and pharmacodynamics of remifentanil. I. Model development. Anesthesiology 1997; 86: 10-23.

10. Varvel JR, Donoho DL, Shafer SL. Measuring the predictive performance of computer-controlled infusion pumps. J Pharmacokinet Biopharm 1992; 20: 63-94.

11. Lonnqvist PA, Lofqvist B. Design flaw can convert commercially available continuous syringe pumps to intermittent bolus injectors. Intensive Care Med 1997; 23: 998-1001.

12. Weiss M, Neff T, Gerber A, Fischer J. Impact of infusion line compliance on syringe pump performance. Paediatr Anaesth 2000; 10: 595-9. 